\title{
Modeling Scale-Up Effects on a Small Pilot-Scale Fluidized-Bed Reactor for Fuel Ethanol Production*
}

\author{
O. F. Webb**, Brian H. Davison, and T. C. Scott \\ Chemical Technology Division \\ Oak Ridge National Laboratory \\ PO Box 2008 MS-6226 \\ Oak Ridge, TN 37831-6038 \\ A Scientific Note Submitted to Applied Biochemistry and Biotechnology \\ at the \\ Seventeenth Symposium on Biotechnology for Fuels and Chemicals \\ Vail, Colorado \\ May 7-11, 1995

\section{DISCLAIMER}

\begin{abstract}
This report was prepared as an account of work sponsored by an agency of the United States Government. Neither the United States Government nor any agency thereof, nor any of their employees, makes any warranty, express or implied, or assumes any legal liability or responsibility for the accuracy, completeness, or usefulness of any information, apparatus, product, or process disclosed, or represents that its use would not infringe privately owned rights. Reference herein to any specific commercial product, process, or service by trade name, trademark, manufacturer, or otherwise does not necessarily constitute or imply its endorsement, recommendation, or favoring by the United States Government or any agency thereof. The views and opinions of authors expressed herein do not necessarily state or reflect those of the United States Government or any agency thereof.
\end{abstract}

*Research supported by the Office of Transportation Technologies of the U.S. Department of Energy and administered by the National Renewable Energy Laboratory under contract DE-AC05-84OR21400 with Martin Marietta Energy Systems, Inc.

** Author to whom all correspondence should be addressed.

DISTRIBUTION OF. THIS DOCUMENT IS UNLIMITED

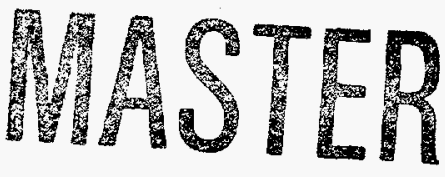<smiles>C1CC2CCC(C1)C21CC1</smiles> 


\section{DISCLAIMER}

Portions of this document may be illegible in electronic image products. Images are produced from the best available original document. 


\title{
Modeling ScaleUp Effects on a Small Pilot-Scale Fluidized-Bed Reactor for Fuel Ethanol Production
}

\author{
OREN F. WEBB, BRIAN H. DAVISON, AND T. C. SCOTT \\ Oak Ridge National Laboratory \\ P.O. Box 2008, MS-6226
}

Oak Ridge, TN 37831-6226 (615) 241-4655

\section{SCIENTIFIC NOTE}

Key words: Ethanol, dextrose, fermentation, fluidized-bed reactor.

\section{INTRODUCTION}

Domestic ethanol use and production are presently undergoing significant increases along with planning and construction of new production facilities. Significant efforts are ongoing to reduce ethanol production costs by investigating new inexpensive feedstocks (woody biomass) and by reducing capital and energy costs through process improvements.

A key element in the development of advanced bioreactor systems capable of very high conversion rates is the retention of high biocatalyst concentrations within the bioreactor and a reaction environment that ensures intimate contact between substrate and biocatalyst. One very effective method is to use an immobilized biocatalyst that can be placed into a reaction environment that provides effective mass transport, such as a fluidized bed. Previous studies have shown that such systems may be more than 10 to 50 times as productive as conventional technology ${ }^{1,2}$. To enable effective design, predictive mathematical descriptions are needed based on fundamental principles and accepted correlations that describe important physical phenomena. Others have attempted to develop such predictive models in a less complete manner. These were summarized earlier ${ }^{4}$.

In this manuscript, we describe refinements and semi-quantitatively extend the predictive model of Petersen and Davison ${ }^{3,4}$ to a multiphase fluidized-bed reactor (FBR) that was scaled-up for ethanol production. Petersen and Davison ${ }^{3,4}$ previously included in the model (1) published substrate- and product-limited reaction kinetics, (2) internal diffusion-reaction for the beads, and (3) effects of column taper, pressure, and fluid flow 
rates on holdups for gas, solid, and liquid phases and axial dispersion coefficient. Axial concentration profiles were evaluated by solving coupled differential equations for glucose and carbon dioxide. The pilot-scale FBR ( 2 to $5 \mathrm{~m}$ tall, 10.2-cm ID, and 23,000 $\mathrm{L} \mathrm{month}^{-1}$ capacity) was scaled up from bench-scale reactors (91 to $224 \mathrm{~cm}$ long, 2.54 to $3.81 \mathrm{~cm} \mathrm{ID}$, and 400 to $2,300 \mathrm{~L}_{\text {month }}{ }^{-1}$ capacity). Significant improvements in volumetric productivites (50 to $200 \mathrm{~g} \mathrm{EtOH} \mathrm{h}^{-1} \mathrm{~L}^{-1}$ compared with 40 to 110 for bench-scale experiments and 2 to 10 for reported industrial benchmarks) and good operability were demonstrated..

\section{MATERIALS AND METHODS}

Cultures of Zymomonas mobilis NRRL-B-14023 were grown under nitrogen in media consisting of yeast extract $\left(10 \mathrm{~g} \mathrm{~L}^{-1}\right)$, dextrose $\left(20 \mathrm{~g} \mathrm{~L}^{-1}\right)$, and phosphate $\left(2.0 \mathrm{~g} \mathrm{~L}^{-1}\right)$ at $\mathrm{pH} 6.0$ in a $500 \mathrm{~L}$ fermentation.

The immobilization method and measurement are described in detail elsewhere ${ }^{2,5}$. In summary, bacteria were removed from solution by centrifugation; mixed with a solution of $4 \mathrm{wt} \% \mathrm{~K}$-carrageenan and $3 \mathrm{wt} \%$ $\mathrm{Fe}_{2} \mathrm{O}_{3} ;$ and formed into gel beads in $0.3 \mathrm{M} \mathrm{KCl}$ solution. Iron oxide was added to increase the specific gravity and improve bead retention in the column. Bead sizes were $1.6 \pm 0.4 \mathrm{~mm}$. Volumetric bacterial concentrations were $60 \pm 20 \mathrm{~g}$ (dry weight) $\mathrm{L}^{-1}$ beads.

The previously described reactor configuration ${ }^{2}$ is summarized for the readers convenience. The major components of the FBR included (1) separate media storage containers, (2) peristaltic pumps for pumping media to the reactor, (3) in-line mixers, (4) systems for control and monitoring of $\mathrm{pH}$ and temperature, and (5) temperature and $\mathrm{pH}$. The pilot-scale FBR was $2.5 \mathrm{~m}$ by $10.16 \mathrm{~cm}$ with a $1.2 \mathrm{~m}$ disengagement section. The $\mathrm{pH}$ and internal temperature ranged from 4.9 to 5.1 and $30^{\circ} \mathrm{C}$ to $36^{\circ} \mathrm{C}$, respectively. The reactor was not sterilized, nor were the feed streams. Minimal procedures were used for mitigating contaminant growth and included rinsing lines, refrigeration, cleaning feed containers, and storing key medium components in separate containers.

The fluid dynamics within the pilot FBR were a complex function of reaction rate, dextrose feed concentration, solids loading, and gas-liquid-solid properties. The fluidization of the bed changed rapidly with axial position due to significant changes in fluid flow rates and physical properties. For example, entering liquid 
feed had a density of 1.07 , whereas the effluent has a density of 0.98 . Fluidization of the bed could be thought of as occurring in three visually distinguishable zones. The first zone, located at the bed entrance, acted as an expanded bed. The second zone, fluidized by gas product, started a few centimeters above the entrance and encompassed most of the bed. The third zone, termed the disengagement section, was characterized by significant mixing produced by large quantities of gas and a relatively low biocatalyst population.

\section{MATHEMATICAL MODEL \& DISCUSSION}

A model was developed ${ }^{3,4}$ describing the three-phase FBR for fermentation of dextrose to ethanol using immobilized $Z$. mobilis. This model is reiterated here with refinements. The predictive model fit bench-scale data quite well; however, the general applicability was restricted because the range of fluid hydrodynamic conditions, phase holdups, and gas density changes was small for bench-scale conditions. To describe the system, the biocatalyst as well as the bulk fluid phase must be described. Once the bead boundary value problem is solved including diffusion through the bead with reaction, concentration profiles within the bulk solution maybe solved for as a function of axial position.

\section{Bead and Bulk Phase Governing Equations}

The bead effectiveness factor model was unchanged from previous work ${ }^{4}$. Lee and Rodgers ${ }^{6}$ described $^{-}$ the conversion of glucose to ethanol and carbon dioxide by $Z$. mobilis using a modified Michaelis-Menten equation including substrate and product inhibition. Ethanol formation is related to substrate utilization by a simple algebraic mass balance. The distribution within the particle was described using a boundary value differential equation which included the effects of simple diffusion and reaction within the particle. Boundary conditions included; (1) a symmetric substrate concentration at the bead center and (2) substrate concentration at the bead surface equal to the bulk concentration due to substantial mixing in the fluidized bed.

A dispersed plug flow model was employed to describe the substrate profile in the bulk phase: 


$$
\frac{d^{2} s}{d z^{2}}=\frac{L}{D_{z}}\left(\frac{Q_{L}}{\pi R^{2}}-\frac{1}{L} \frac{d D_{z}}{d z}-\frac{2 M D_{z}}{R}\right) \frac{d s}{d z}+\frac{L^{2}}{D_{z} C_{0}} \eta(s) \varepsilon_{s} r_{A} .
$$

The problem is formulated to be general enough for use with tapered as well as straight columns. Potential boundary conditions include Danckwerts ${ }^{7}$ modified to include the taper as well as simple conditions assuming no dispersion across the screen used to hold beads in the reactor.

The carbon dioxide is assumed to flow through the reactor in a plug flow fashion only in the gas phase. The carbon dioxide profile can be solved for using a differential equation coupled to equation (1) through the reaction rate:

$$
\frac{d C O_{2}}{d z^{*}}=\frac{r_{A} \varepsilon_{s} \eta L}{U_{L}} Q_{L} y_{\left(O_{2} / s\right.}
$$

The model was solved with a software package which implements the method of spline collocation ${ }^{8,9}$. The Jacobians of the equations and boundary conditions, defined as the partial derivative of the differential equations with respect to the dependent variables, were required by the software package. Due to the complex manner that carbon dioxide and substrate flow rates enter into the dispersion equation, the Jacobians were evaluated numerically. The step size was optimized per Dennis and Schnabel ${ }^{10}$. For improved numerical stability, an analytical Jacobian could be developed.

\section{Prediction of Gas, Solid, and Liquid Holdup}

If the feed contains large concentrations of dextrose, then very large volumes of carbon dioxide will be formed relative to the liquid stream. The solid holdup is determined by subtracting liquid and gas contributions. Gas and liquid holdups were estimated using the correlation of Begovich-Watson ${ }^{11}$ :

$$
\begin{aligned}
& \varepsilon_{g}=\alpha \times U_{g}^{\beta} \times d_{p}^{\gamma} \times D_{c}^{\delta} . \\
& \varepsilon_{l}=\sigma \times U_{l}^{\zeta} \times U_{g}^{\zeta} \times\left(\rho_{s}-\rho_{l}\right)^{\theta} \times d_{p}^{\mathrm{\iota}} \times \mu_{l}^{\kappa} \times D_{c}^{\lambda}-\varepsilon_{g} .
\end{aligned}
$$


The correlation parameters (alpha, sigma, and superscript Greek characters) are based on the 39 hydrodynamic experiments conducted by Davison ${ }^{12}$ using a $7.62 \mathrm{~cm}$ FBR. Equations (3) and (4) are not applicable in the absence of gas flow, thus entrance holdups were estimated using an artificial gas flow rate $0.1 \%$ of the $U_{g}$ at total conversion. Previously, the Richardson-Zaki ${ }^{13}$ correlation was used to predict holdups in two-phase flow when the Begovich-Watson correlation was not applicable (i.e., at the bed entrance); however, predictions were prone to dramatic changes at the bed entrance. This first refinement reduced the variation at the bed entrance to a range typical of entrance conditions (Fig. 1a). Also, exclusive use of the Begovich-Watson correlation potentially simplifies the algorithm and allows the development of analytical Jacobians. Equations (3) and (4) do not predict minimum fluidization velocities; thus, in this method, the solid holdup was bounded using the actual settled bed holdup. This second refinement was very obvious in Fig. $1 \mathrm{~b}$ where the taper caused significant reductions in flow rates at the top of the bed. The absence of these refinements did not produce large changes in the concentration profiles (Fig. 2a-b) for previously published data ${ }^{4}$. The small changes produced by the correction did, however, reduce differences between observed and predicted values in all cases. The reactor used in these cases was tapered; thus, correction effects on holdups might be more obvious than when a straight walled FBR is used. Thus, these refinements are important for the FBR boundary condition where little or no gas is present and for cases where phase velocities drop below those required for minimum fluidization.

Actual and predicted performance of the pilot-scale reactor is depicted in Fig. 3a-d. In all cases, the algorithm underpredicted pilot-scale performance. Improvements in the Begovich-Watson constants by reevaluation in the pilot-scale FBR would probably have small effects in reducing these differences. Wall effects, significant in determining behavior of gases in enclosed multiphase flow, ${ }^{14}$ could have significantly affected evaluation. Slug-type behavior was observed in the bench-scale experiments ${ }^{1}$ but not in the pilot-scale reactor ${ }^{2}\left(10.16 \mathrm{~cm}\right.$ ID) nor the $7.62 \mathrm{~cm}$ FBR used by Davison et al. ${ }^{12}$ for measuring the Begovich-Watson parameters. Clift et al. ${ }^{14}$ measured the maximum stable size for single air bubbles in water as $4.9 \mathrm{~cm}$. Of course, interactions with solids, other gas bubbles, hydrodynamic 
turbulence, and wall effects will reduce this value. Typical bubble diameters for the pilot reactor were on the order of a centimeter or less by visual inspection. Case $\mathrm{F}$ further supports this hypothesis. Bed activity approached maximal values throughout the reactor because the solid holdup did not vary significantly from the maximum (Fig. 4).

\section{Determination of $\mathrm{U}_{\mathrm{l}}, \mathrm{U}_{\mathrm{g}}$, and Liquid Dispersion}

For tapered reactors, the column radius will change superficial gas and liquid velocities. Dispersion was calculated using the correlation of Kim et al. ${ }^{15}$,

$$
P e_{z}=\left(\frac{d_{p} U_{l}}{D_{z}}\right)=C\left(\frac{d_{p}}{D_{c}}\right)^{1.60}\left(\frac{U_{l}}{U_{l}+U_{g}}\right)^{1.03}
$$

This correlation includes column and bead diameter effects as well as liquid and gas superficial velocity effects.

The value of the constant $C$ is assigned different values that depend upon whether generated bubbles are coalescing or remain dispersed. The argument can be made that $\mathrm{C}$ has some relationship to wall effects with respect to gas-phase behavior. Cases E-G in Fig. 3a-d depict the effect of different values of $\mathrm{C}$ on predicted concentration profiles within the pilot-scale FBR. For the examined cases, changing the value of $\mathrm{C}$ did not change model predictions significantly. Using a linear relationship to relate static head and reactor position, the derivative of the dispersion coefficient can be derived from eq. (5) for use in eq. (1):

$$
\frac{d D_{z}}{d z}=\frac{1.03 f_{1}^{0.03} f_{2}}{f_{3}^{1.03} f_{4}^{0.34}}+\frac{1.03 k_{1} L \tau f_{1}^{1.03}}{f_{3}^{2.03} f_{4}^{0.34}}-\frac{0.34 L M \tau f_{1}^{1.03}}{f_{3}^{1.03} f_{4}^{0.84}}
$$

where

$$
\begin{aligned}
& f_{1}=C O_{2} \varphi-L z \omega+\phi \\
& f_{2}=\tau\left(\frac{d C O_{2}}{d z} \varphi-L \omega\right), \\
& f_{3}=\psi-k_{1} L z \\
& f_{4}=L M z+R_{0} .
\end{aligned}
$$


This relationship states dependent variables in explicit terms of position and potentially allows analytical Jacobians to be developed.

\section{SUMMARY}

Demonstrated pilot-scale productivities were in all cases higher than model predictions (Fig. 3a-d). In Case E, with almost complete substrate conversion, the predicted and actual profiles were very similar. The model did a good job of predicting concentration profiles for the bench-scale reactor ${ }^{4}$. The range of pilot-scale productivities $^{2}$ was higher than those observed at the bench-scale ${ }^{1}$. This tends to indicate that economic impacts of the FBR for ethanol production might be greater than the previously estimated 5 to 8 cent savings per gallon ${ }^{16}$ relative to batch processes. Even if the biocatalyst concentration is increased $33 \%$ to $80 \mathrm{~g} \mathrm{~L}^{-1}$ (dry weight), the model continues to significantly underestimate substrate conversion and volumetric productivity in all the pilotscale cases examined. At the measured biomass concentration of $60 \mathrm{~g}$ (dry weight) $\mathrm{L}^{-1}$, bacteria make up a majority of the pellet. Free biomass concentrations were on the order of one to two magnitudes less than the immobilized concentrations. Average yields (96\% of theoretical) for a continuous eight week experiment ${ }^{17}$ with the pilot-scale reactor were similar to those of an eight week experiment ( $97 \%$ of theoretical) using the benchscale reactors ${ }^{4}$. Further, similar to the eight week bench-scale experiment, the biocatalyst used in the pilot-scale showed good activity throughout the trial ${ }^{17}$. Differences between bench-scale and scaled-up FBR include wall and pressure effects, and holdup regimes for the gas, liquid, and solid phases. Pressure effects on the gas phase may have been more significant in the pilot-scale reactor because of the significant difference in reactor height $(3.7 \mathrm{~m})$ relative to the bench-scale reactor (less than $1 \mathrm{~m}$ ).

Model refinements resulted in (1) better estimates of liquid, solid, and gas holdups; (2) inclusion of some wall effects, and (3) better estimates of Jacobians through improved step size control. Potential areas for improving the model include basing the carbon dioxide differential equation on phase density and velocities, inclusion of carbon dioxide solubility, and better correlations for liquid phase dispersion. The pilot-scale FBR continues to demonstrate significant promise for industrial application. New model refinements are needed to 
account for very high productivities measured in the pilot-scale reactor. Use of a single holdup correlation and limiting the range of solid holdup improved model accuracy and potentially allows development of analytical Jacobians for improved model stability. Error induced by applying Begovich-Watson parameters measured at the bench-scale to the pilot-scale reactor could not solely account for differences in predicted and measured FBR behavior.

\section{ACKNOWLEDGMENTS}

Research supported by the Office of Transportation Technologies of the U. S. Department of Energy and administered by the National Renewable Energy Laboratory under contract DE-AC05-84OR21400 with Martin Marietta Energy Systems, Inc. The authors appreciate the advice of Dr. James N. Petersen of Washington State University who helped developed the original computer code.

\section{SYMBOLS}

\section{Constant eq.(5)}

$C_{0} \quad$ Feed concentration, $\mathrm{g} \mathrm{L}^{-1}$

$\mathrm{CO}_{2}$ Carbon dioxide flow rate $\mathrm{g} \mathrm{h}^{-1}$

$d_{p} \quad$ Particle diameter, $\mathrm{cm}$

$D_{c} \quad$ Column diameter, $\mathrm{cm}$

$D_{\text {dexirise }}$ Diffusion coefficient of dextrose, $\mathrm{cm}^{2} \mathrm{~s}^{-1}$

$D_{z} \quad$ Dispersion coefficient, $\mathrm{cm}^{2} \mathrm{~s}^{-1}$

$k_{1} \quad$ Constant in pressure relationship, $\mathrm{N} \mathrm{in} \mathrm{cm}^{-1}$

$L \quad$ Bed length, $\mathrm{cm}$

$M \quad$ Taper ratio, $\mathrm{cm} \mathrm{cm}^{-1}$

$p \quad$ Product concentration, $\mathrm{g} \mathrm{L}^{-1}$ 
$P e_{z} \quad$ Peclet number

$Q_{L} \quad$ Volumetric flow rate, $\mathrm{L} \mathrm{h}^{-1}$

$r_{A}(s)$ Reaction rate, $\mathrm{g} \mathrm{L}^{-1} \mathrm{~h}^{-1}$

$R \quad$ Bead radius, $\mathrm{cm}$

$R_{0} \quad$ Diameter at bottom of tapered column, $\mathrm{cm}$

$s \quad$ Substrate concentrations, $\mathrm{g} \mathrm{L}^{-1}$

$U_{g} \quad$ Superficial gas velocity, $\mathrm{cm} \mathrm{h}^{-1}$

$U_{1} \quad$ Superficial liquid velocity, $\mathrm{cm} \mathrm{h}^{-1}$

$x \quad$ Biomass concentration, $\mathrm{g} \mathrm{L}^{-1}$ (dry weight basis)

$Y_{\mathrm{CO}_{2} / \mathrm{s}}$ Carbon Dioxide yield coefficient, $0.49 \mathrm{~g} \mathrm{~g}^{-1}$

$z \quad$ Dimensionless axial position

$\varepsilon_{g} \quad$ Gas phase holdup

$\varepsilon_{1} \quad$ Liquid phase holdup

$\varepsilon_{s} \quad$ Solid phase holdup

$\eta \quad$ Effectiveness factor

$\mu_{1} \quad$ Viscosity, $\mathrm{g} \mathrm{cm}^{-1} \mathrm{~s}^{-1}$

$\rho_{s} \quad$ Solid density, $\mathrm{g} \mathrm{L}^{-1}$

$\rho_{l} \quad$ Liquid density, $\mathrm{g} \mathrm{L}^{-1}$

$\xi \quad$ Dimensionless radial position in the bead

$\tau \quad$ Constant, $\mathrm{cm}^{-0.59} \mathrm{~mol}^{1.03} \mathrm{~g}^{-1.03} \mathrm{~s}^{0.03}$ eq. (7)

$\phi \quad$ Constant, $\mathrm{N} \mathrm{g} \mathrm{mol}^{-1} \mathrm{~cm} \mathrm{~s}^{-1}$ eq. (7)

$\varphi \quad$ Constant, $\mathrm{N} \mathrm{cm} \mathrm{mol}{ }^{-1}$ eq. (7)

$\psi \quad$ Constant-Pressure at bottom of reactor, $\mathrm{N} \mathrm{cm}^{-2}$ eq. (7) 


\section{FIGURES}

Fig. 1a. Modification of Holdup Correlation. Exclusive use of a single correlation with corrections reduced holdup variation at the bed entrance to a range typical of entrance conditions. The Begovich-Watson is not applicable in the absence of gas flow (i.e., at the bed entrance). Previously, the Richardson-Zacki correlation was used to correct for this deficiency; however, predicted holdups were apt to drastic changes.

Fig. 1b. Bounding minimum fluidization velocity. With a tapered column, continuous phase velocity may drop below that required for minimum fluidization. A simple bound on the maximum solid phase holdup maintains holdup estimates within a reasonable range.

Fig. 2a-b. Effect of holdup corrections on concentration profiles. Concentration profiles were not significantly affected by the holdup corrections at the bed entrance and in the upper column. The identification of Cases A-D were retained from Petersen \& Davison ${ }^{4}$ (Cases C \& D omitted).

Fig. 3a-d. Comparison of measured and predicted performance for the pilot-scale reactor. Although the model adequately predicted bench-scale FBR performance, the model significantly under-predicted pilot-scale FBR performance. Differences in the bench- and pilot-scale FBRs could include wall effects and pressure effects on the compressible phase. The value of $\mathrm{C}$ was assigned depending upon whether gas bubbles were coalescing or remained dispersed. Model predictions did not significantly change over the range of $\mathrm{C}$ values.

Fig. 4. Holdup effects in the presence of low liquid flow rates for the pilot-scale FBR. Bed activity approached maximal values throughout the reactor because the solid holdup did not vary significantly from the maximum. This case supports the hypothesis that reevaluation of the Begovich-Watson parameters in the pilot-scale FBR would have little impact on reducing the differences in measured and predicted performance.

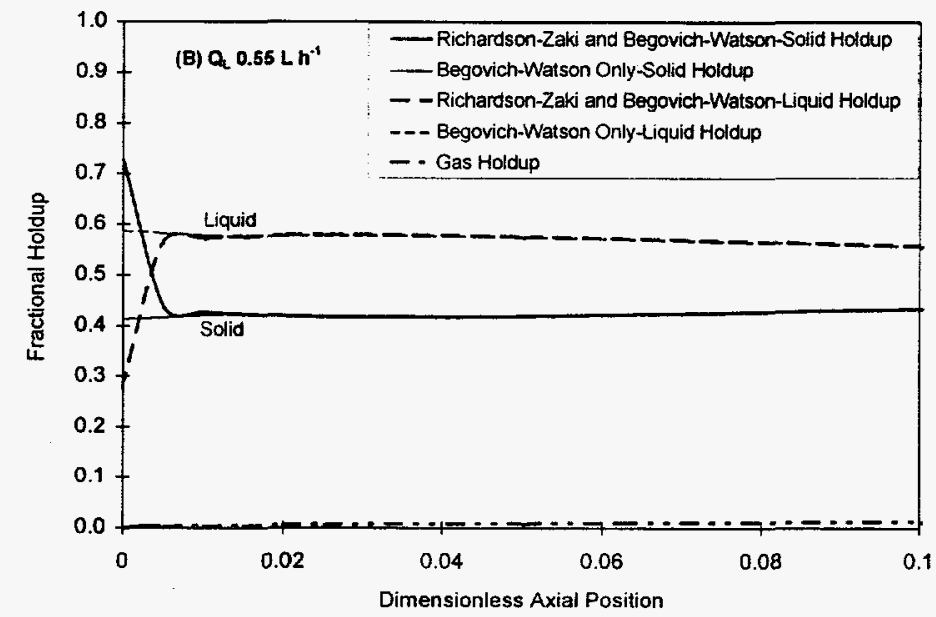



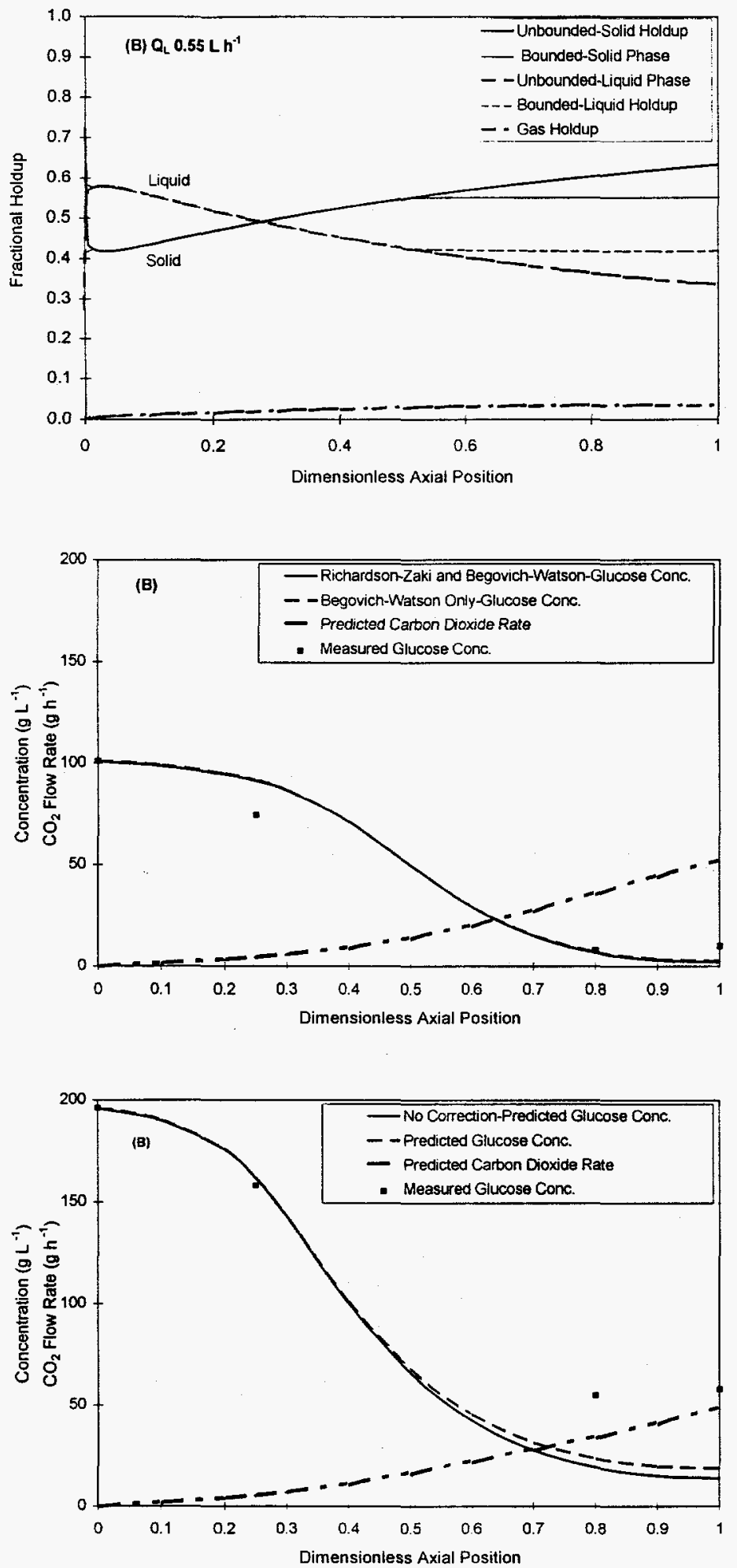

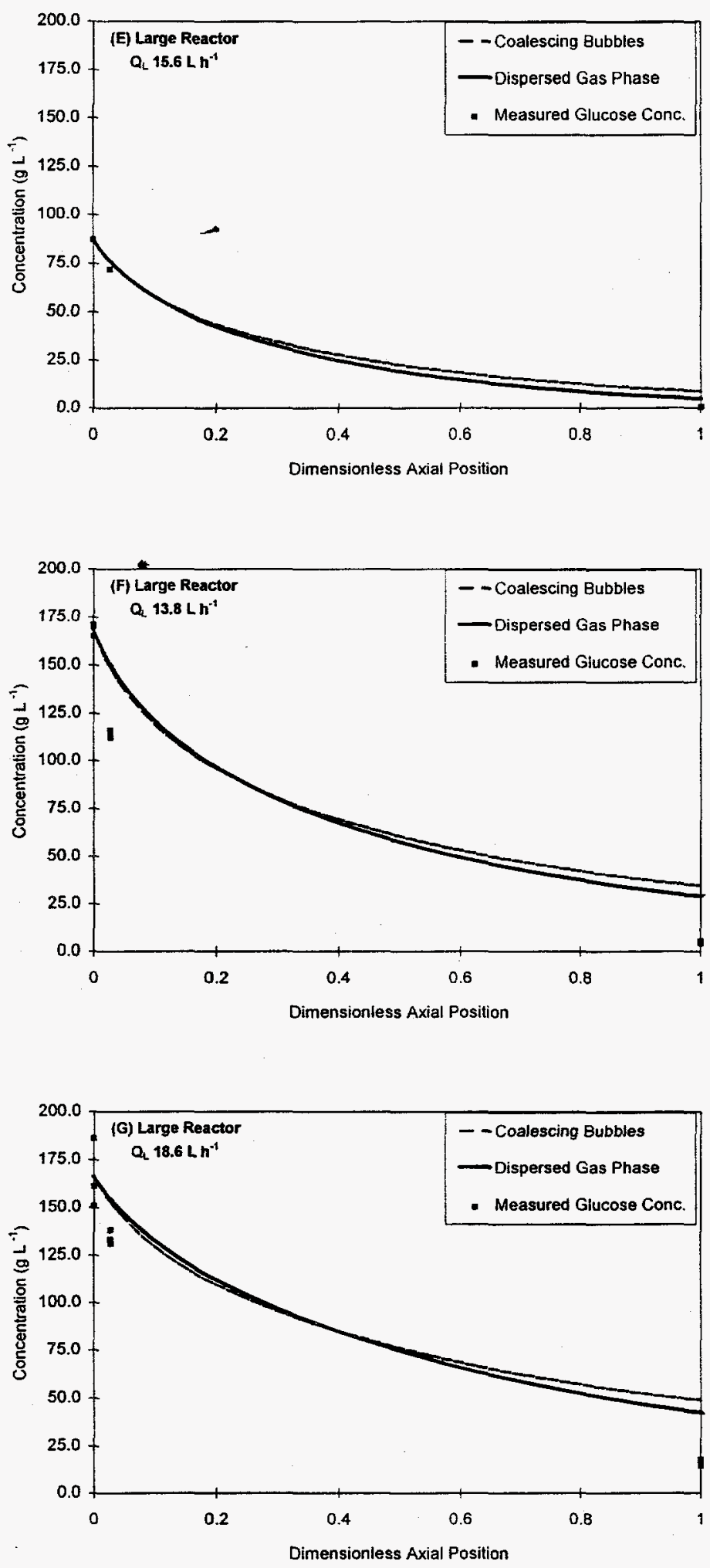

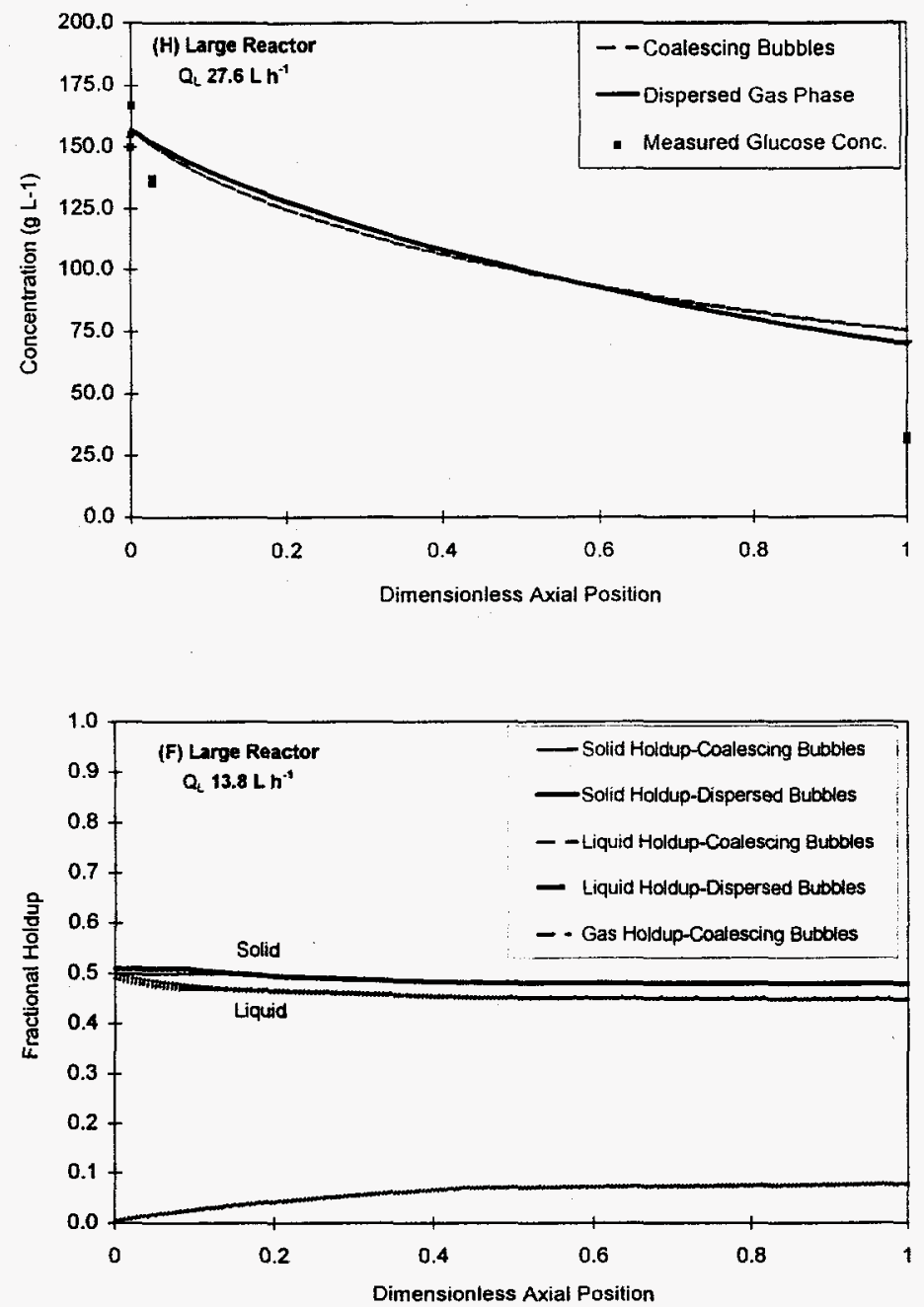


\section{References}

1. Davison, B. H. and Scott, C. D. (1988), Appl. Biochem. Biotechnol. 18, 19.

2. Webb, O. F., Scott, T. C., Davison, B. H., and C. D. Scott, (1995), Appl. Biochem. Biotechnol. (in Press).

3. Petersen, J. N. and Davison, B. H. (1991), Appl. Biochem. Biotechnol. 28, 685.

4. Petersen, J. N. and Davison, B. H. (1995), Biotechnol. Bioeng. 46, 139.

5. Scott, C. D. (1987), Ann. NY Acad. Sci. 501, 487.

6. Lee, K. J. and Rogers, P. L. (1983), Chem. Eng. J. 27, B31.

7. Danckwerts, P. V. (1953) Chem. Eng. Sci. $2,1$.

8. Ascher, U., Christiansen, J., and Russel, R. D. (1979) Math. Comput. 33, 659.

9. Ascher, U., Christiansen, J., and Russel, R. D. (1979) ACM TOMS. 7, 209.

10. Dennis, J. E., Schnabel, R. B. (1983) Numerical Methods for Unconstrained Optimization and

Nonlinear Equations, Prentice-Hall, Inc., Englewood Cliffs, New Jersey.

11. Begovich, J. M. and Watson, J. S., (1978), in: Davison, J. F. and Keairns, D. L., eds., Fluidization, Cambridge University Press, Cambridge, p. 190.

12. Davison, B. H. (1990), Ann. NY Acad. Sci. 589, 670.

13. Richardson, J. F. and Zaki, W. N., (1954), Trans. Instn. Chem. Engrs. 32, 35.

14. Cliff, R., Grace, J. R., and Weber, M. E., (1978), Bubbles. Drops, and Particles, Academic Press, New York.

15. Kim, S. D., Kim, S. H. and Han, J. H. (1992) Chem. Eng. Sci. 47, 3419.

16. Harshbarger, D., Bautz, M., Davison, B. H., Scott, T. C., and Scott, C. D. (1995), Appl. Biochem. Biotechnol. (In Press).

17. Webb, O. F. (1995) Biotechnol. Bioeng. (In Preparation). 